\title{
The Simulation Analysis of Novel Magnetically Controlled Reactor Characteristic
}

\author{
Guosheng Zhao, Bin Sun* and Pei Li \\ Zhengzhou University, No.100 Science Avenue, High-Tech Zone, Zhengzhou, Henan, China \\ ${ }^{*}$ Corresponding author
}

\begin{abstract}
At present, the main research methods are Matlab/simulink and Ansoft maxwell. When modeling and simulating with Matlab/simulink software, there will be shortcomings in the simulation as the special structure of the model and material parameters cannot be set. The modeling and simulating with Ansoft maxwell has some limitations since it cannot build complex control circuit to achieve the response characteristics analysis. In order to improve engineering reliability and the authenticity of the simulation results. based on the introduction of the structure, working principle and the simulation research method of two-stage magnetic valve MCR, this paper introduces the novel method of combining Simplorer with Maxwell to realize the multi-physical domain simulation of the field road. The above shortcomings are made up. Thus, this method is used to analyze the harmonic characteristics and response characteristics of the two-stage magnetic valve MCR. It provides an experimental theoretical basis for designing a controllable reactor with better performance.
\end{abstract}

Keywords - the two-stage magnetic valve MCR; simulation method; maxwell; simplorer; harmonic; response

\section{INTRODUCTION}

As a new type of reactive power compensation device, optimization and analysis of harmonic characteristics and response characteristics of MCR play an important role in improving the quality of power supply and improving the economic benefits of power grid. At present, there are mainly theoretical analysis methods [1], Matlab/simulink simulation analysis method and Ansoft Maxwell simulation analysis method for the characteristic analysis of controllable reactor. Among them, the theoretical analysis method in theory introduces the working principle, a novel controllable reactor mathematical model and characteristic analysis, but the analysis cannot directly reflect its characteristics; Matlab/simulink simulation could build simulation circuit and transformer equivalent model, which includes single-phase saturated controllable reactor [2-4], single-phase three column MCR[5,6], single phase four MCR[7-11], MCR[12] and threephase three pole. Though the characteristic of models analysis are analyzed by this way, the material parameters and special structure of model cannot be disposed by Simulink. Besides that, the electromagnetic simulation cannot be achieved . So the simulation results may have a significant deviation from the actual ; Ansoft Maxwell simulation can analyze electromagnetic simulation and harmonic characteristics of these models which includes single-phase tetrastyle MCR[13], three-phase six pole MCR[14] and orthogonal core three-phase MCR [15] , but the method cannot realize the response characteristic analysis of the complex control circuit because of its simple circuit. Thus it also has some limitations. This paper will introduce the new method of joint simulation of Simplorler and Maxwell[16,17]. Simplorer is a software of powerful multidomain electromechanical system design and simulation analysis, which is used for the modeling, design, simulation analysis and optimization of electromechanical integration systems such as electromagnetism and control. Thus Simplorer with Maxwell to realize the multi-physical domain simulation of the field road, which will greatly improve the properties of the real and accuracy.

\section{ANALYSIS OF THE STRUCTURE AND PRINCIPLE OF TWO- STAGE MAGNETIC VALVE MCR}

\section{A. Two-Stage Magnetic Valve MCR Structure}

Two-stage magnetic valve MCR core structure as shown in figure 1, there are 4 core columns between the upper and lower two yoke, containing about two side yokes and the middle of the two main iron core columns which is composed of three different areas of the core series. The advantage of design is that it can make the core of the magnetic valve more compact, reduce the leakage flux, and reduce the loss of iron core. The area of large section iron core is A, A1 is medium section area and length is $11, \mathrm{~A} 2$ is small section area and length is 12 . It is known from the paper [7,8] that the special structure of the magnetic valve has an optimized effect on the harmonic and response characteristics.
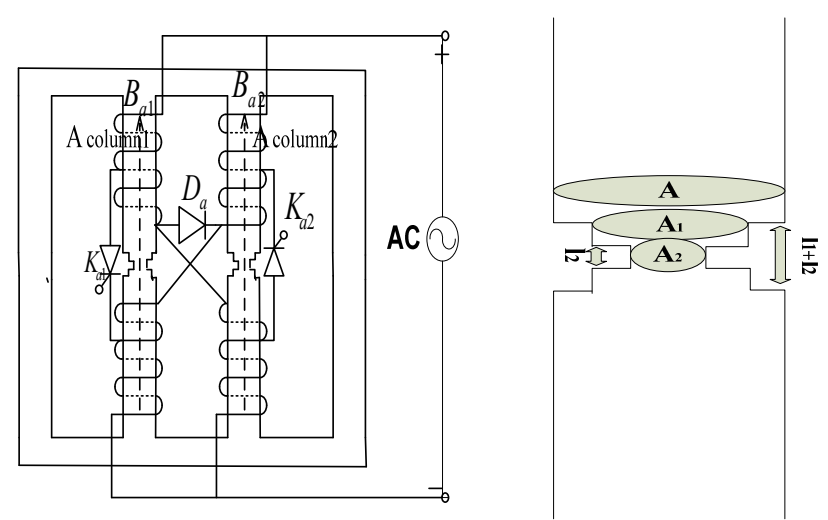

FIGURE I. THE STRUCTURE OF TWO-STAGE MAGNETIC VALVE MCR CORE STRUCTURE 
B. Analysis of the Working Principle of Two-Stage Magnetic Valve Mcr

The principle of MCR is the principle of magnetic saturation[1].The magnetic state working point and magnetic properties are changed to control the magnetic saturation by the excitation of dc controlled current, as to change the reactance of the $\mathrm{AC}$ winding to smooth regulate the capacity of reactor. It is analyzed as shown in figure 2 for the circuit principle diagram. When $\mathrm{Ka} 1$ and $\mathrm{Ka} 2$ are not conducted, there is no self-coupling in the circuit, which is seen from the symmetry structure of the winding. Each main core column has both upper and lower winding turns of $\mathrm{N} / 2$, which have a tap ratio of $\delta=\mathrm{N} 2 / \mathrm{N}$ where connecting thyristor (single phase: $\mathrm{Ka} 1, \mathrm{Ka} 2$ ), The upper and lower winding of the two core columns are intersected and a continuous flow diode (Da) connects between the upper winding. The thyristors mainly acts as the rectifier and the dc current after rectification can be used as the excitation current of the reactor. At last, sinusoidal voltage source of the power grid is connected in parallel with the winding of the two core columns (the number of turns of the upper and lower winding is $\mathrm{N}$ ).

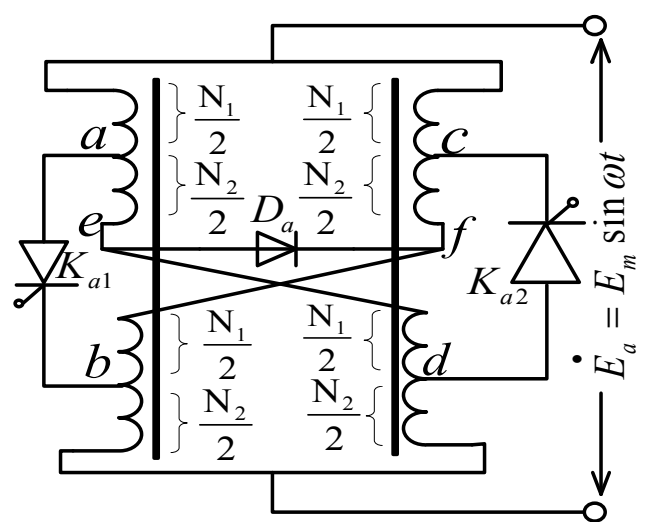

FIGURE II. THE PRINCIPLE DIAGRAM OF THE CIRCUIT

It can be seen from figure 2 that sinusoidal voltage source connected to $\mathrm{MCR}$ is $\dot{E}_{a}=E_{\mathrm{m}} \sin (\omega t)$.On the time of $0 \leq \omega t \leq \pi$ and $\omega t=\alpha$, Ea is positive .The thyristor Kal receives positive voltage and $\mathrm{Ka} 2$ receives the reverse voltage. When giving the Ka1 trigger signal to guide it, $\mathrm{a}$ and $\mathrm{b}$ are equipotential.Self-coupled The power source is selfcoupled from the primary winding(coil number $\mathrm{N}$ ) to deputy winding(coil number N2) where the winding to provide the DC control current to the control circuit;On the time of $\pi \leq \omega t \leq 2 \pi$ and $\omega t=\pi+\alpha$, Ea is negative .If $\mathrm{Ka} 2$ is triggered to lead,the same dc control voltage will be generated.So the size of $\alpha$ can vary the magnitude of control current.By the knowledge of its working principle: The size of the DC control current is changed by changing the thyristor triggering turn-on angle.Then the magnetic saturation of the iron core is changed by changing the current excitation so as to smoothly adjust capacity of MCR.

\section{MODEL ESTABLISHMENT AND EXPERIMENTAL PRINCIPLE ANALYSIS}

\section{A. Model Establishment}

Ansys Maxwell software is used to establish the 2D simulation model of MCR, the magnetization curve of silicon steel sheet and two-stage magnetic valve MCR as shown in figure 3 and figure 4 .The main parameters as follows:(The unit is $\mathrm{mm}$ ) is 120

Main core: Length is 1010 , Height is 1220 , and Thickness

Winding Coil_dc: the inner radius is $80 * 80 * 200$, and the outer radius is $95 * \bar{*} 95200$

Winding Coil_ac: the inner radius is $105 * 105 * 405$, and the outer radius is $120 * 120 * 405$

Inside and outside the winding spacing of 10 ; winding thickness is 15 ;

Magnetic valve: the section area ratio is $3: 2: 1$, and the height of the valve is 25,25 and 25 in turn.

The iron core column is $140 * 120 * 900$;

Top and bottom two iron yoke: height is 160 .

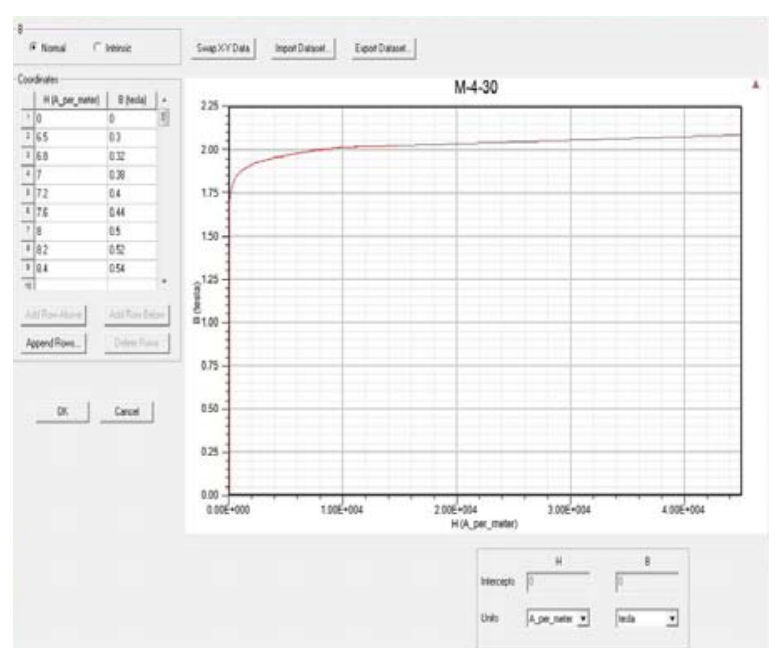

FIGURE III. THE MAGNETIC CURVE FITTING OF SILICON STEEL PLATE 


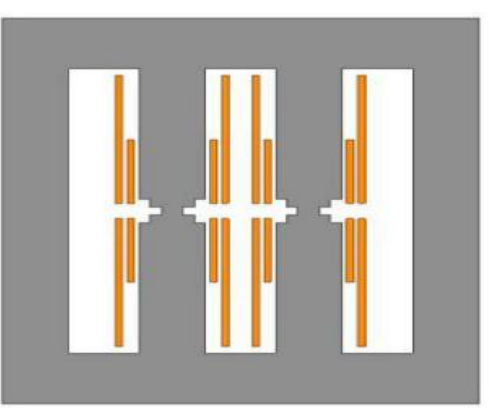

FIGURE IV. TWO-STAGE MAGNETIC VALVE MCR

\section{B. Experimental Principle Analysis}

In this experiment, a new method of combined simulation of Simplorer and Maxwell is introduced to analyze the harmonic characteristics and response characteristics of the two-stage magnetic valve MCR. The principle [1] wiring diagram and the joint simulation wiring diagram of Simplorer and Maxwell, as shown in figure 2 and figure 5, which are the principle of response characteristic analysis of MCR. $E_{1}$ is a single-phase sinusoidal AC power supply, whose peak voltage is $5.5 \mathrm{kV}$. The resistance on the winding is $\mathrm{R}_{2}=\mathrm{R}_{1}=1 \Omega$ and $\mathrm{R}_{3}=\mathrm{R}_{4}=0.01 \Omega$, the winding turn number is $\mathrm{N}=2820$. The tap ratio is $\delta=0.05$. Simulation modeling needs to be imported into Simploer after the model and parameter setting are constructed in Maxwell and complex circuit model is built in Simplorer. When simulation is carried out, the simulation data is exchanged with the Maxwell model to realize the characteristic analysis of the joint simulation.

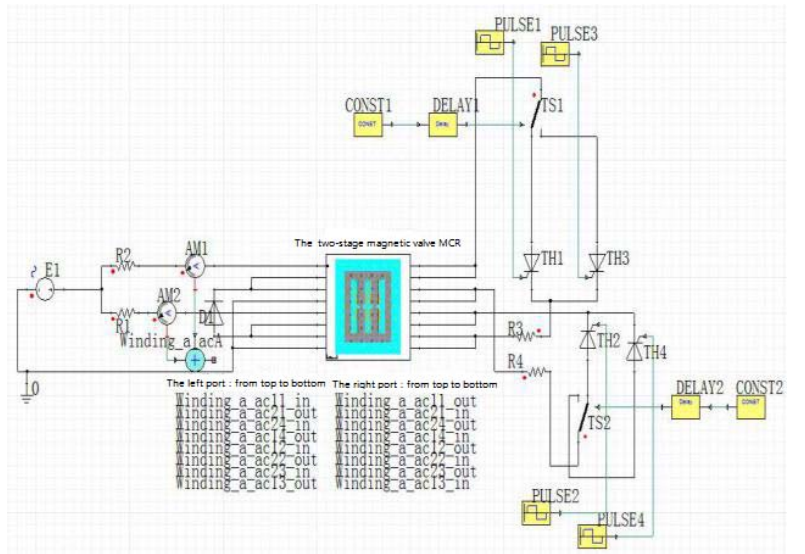

FIGURE V. THE OVERALL WIRING DIAGRAM OF SIMULATION

\section{1) Introduction of main circuit simulation}

The circuit generates the control current in a decoupled manner. Its main circuit detailed simulation wiring is shown in figure 6 below. The upper left long and short winding are connected in series and the same as the lower left winding Then thyristor $\mathrm{TH}_{1}$ is connected between two interfaces. The right side is the same as $\mathrm{TH}_{2}$. Diode $\mathrm{D}_{1}$ is connected between the upper left windings and the right upper winding. Finally, the working current is changed by controlling the trigger Angle of thyristor.

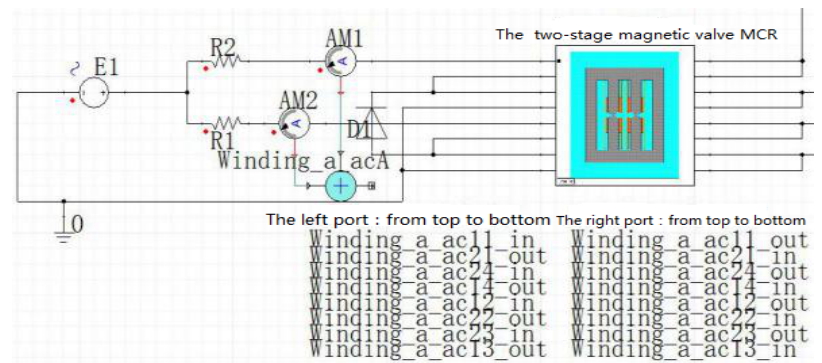

FIGURE VI. THE WIRING DIAGRAM OF MAIN CIRCUIT SIMULATION

\section{2) Introduction of control circuit simulation}

The simulation wiring of control circuit is shown in figure 7 below. The trigger moment of trigger Angle $\alpha$ is equivalent to the corresponding time point in the weekly wave (Frequency $\mathrm{f}=50 \mathrm{~Hz}$ such as $1 \mathrm{~ms}$ equivalent of $18^{\circ}, 2 \mathrm{~ms}$ equivalent of $\left.36^{\circ} \ldots . ..\right)$, The control of working current is realized by using the thyristor with different time points. The control circuit adopts DELAY module, constant module, single pole double throw switch TS, thyristor TH, trigger PULSE module etc to achieve engineering simulation at any time. In the control circuit TH1, TH2 (TH3, TH4) $\alpha \mathrm{TH} 2-\alpha \mathrm{TH} 1=180^{\circ}(\alpha \mathrm{TH} 4-$ $\alpha \mathrm{TH} 3=180^{\circ}$ ). The trigger Angle is Changed from $126^{\circ}$ to $36^{\circ}$ in order to analyze working condition. In this process, the working current is changed from 45 A to 210 A. Therefore, this engineering simulation can meet the demand of real-time reactive power compensation to ensure the stability of system.

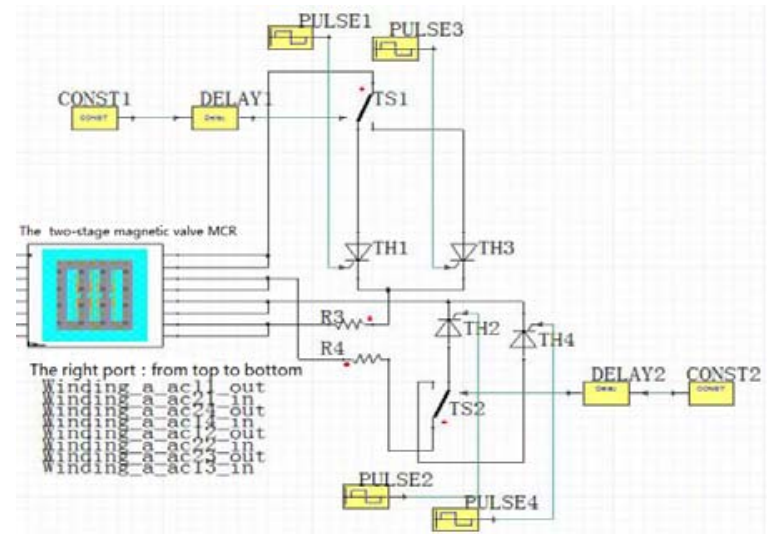

FIGURE VII. THE WIRING DIAGRAM OF CONTROL CIRCUIT SIMULATION

\section{THE HARMONIC AND RESPONSE CHARACTERISTICS ANALYSIS OF TWO-STAGE MAGNETIC VALVE MCR}

\section{A. The Analysis of Harmonic Characteristic}

1) Through the simulation experiment, the working current of the reactor in different control currents is shown in figure 8. 


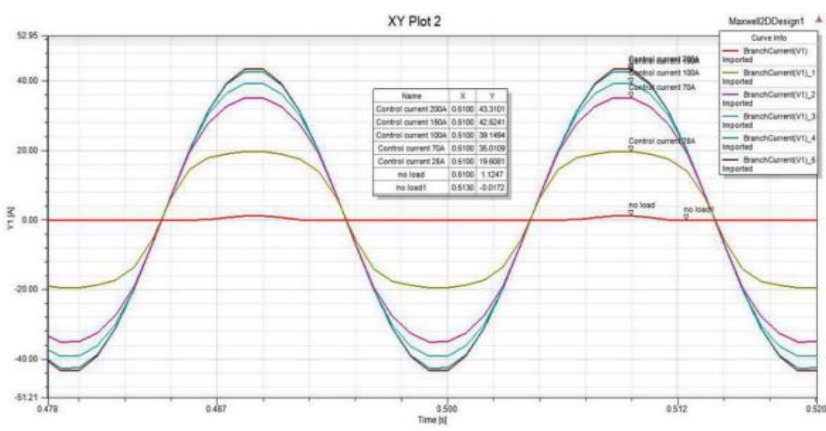

FIGURE VIII. WORKING CURRENT OF TWO-STAGE MAGNETIC VALVE MCR

Now the operating current $40 \mathrm{~A}$ is taken. Then the analysis of harmonic characteristics of the reactor is shown in figure 9.

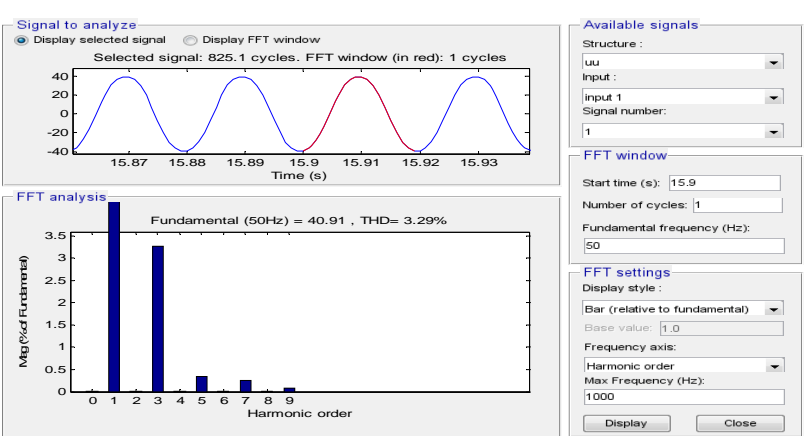

FIGURE IX. THE HARMONIC ANALYSIS OF TWO-STAGE MAGNETIC VALVE MCR CURRENT

TABLE I. THE HARMONIC ANALYSIS OF TWO-STAGE MCR

\begin{tabular}{|c|c|c|c|c|c|}
\hline $\begin{array}{c}\text { The simulation } \\
\text { model }\end{array}$ & \multicolumn{4}{|c|}{ two-stage magnetic valve MCR } \\
\hline $\begin{array}{c}\text { Control winding } \\
\text { current (A) }\end{array}$ & 28 & 70 & 100 & 150 & 200 \\
\hline $\begin{array}{c}\text { Operating winding } \\
\text { current (A) }\end{array}$ & 20 & 35 & 40 & 42 & 43 \\
\hline $\begin{array}{c}\text { Harmonic content } \\
\text { (\%) }\end{array}$ & $\begin{array}{c}15.8 \\
9\end{array}$ & 5.76 & 3.29 & $\begin{array}{c}0.7 \\
1\end{array}$ & $\begin{array}{c}0.1 \\
0\end{array}$ \\
\hline
\end{tabular}

Known from TABLE I, it can change the size of the dc control current by changing the trigger of thyristor. In this way, the magnetic saturation of iron core is changed under the excitation of dc control current. Finally, it can adjust the capacity of the reactor smoothly. When it reaches saturation, the harmonic content of this method is a little bit smaller than the equivalent of the paper [7] with the simulation of matlab. After comparing with the MATALB simulation, it is the method that can show that two-stage MCR greatly reduces the harmonics and obtain better economic benefits.

\section{B. Response Characteristic Analysis}

1) Changing the thyristor trigger angle, (One jump: $126^{\circ} \rightarrow 36^{\circ}$ ) that makes the work current vary from small to large. At last, the response characteristics are shown in figure 10 below.

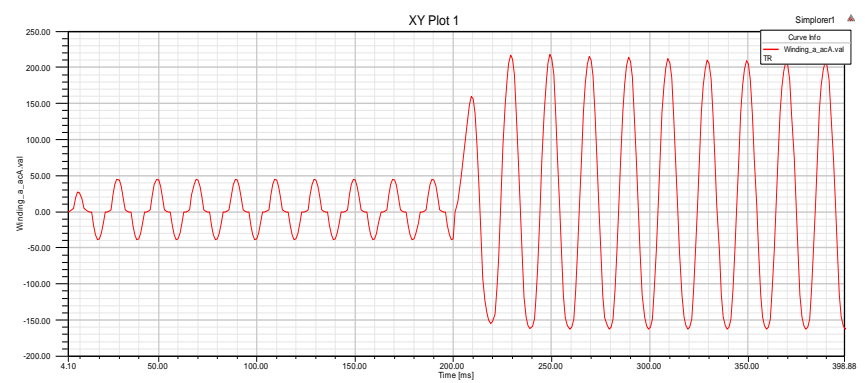

FIGURE X. THE WAVEFORM OF WORKING CURRENT CHANGE AND RESPONSE TIME

Figure 10 shows that the change of peak current from $45 \mathrm{~A}$ to $210 \mathrm{~A}$. When operating current achieves stability, the response time is $15 \mathrm{~ms}$.

2) Changing the thyristor trigger angle, (One jump: $36^{\circ} \rightarrow 126^{\circ}$ ) that makes the work current vary from large to small. At last, the response characteristics are shown in figure 11 below.

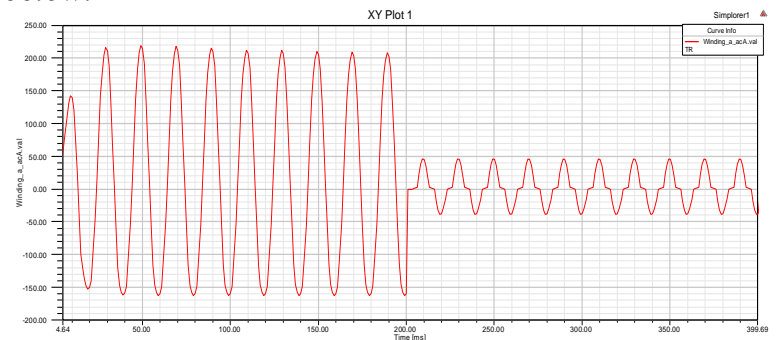

FIGURE XI. THE WAVEFORM OF WORKING CURRENT CHANGE AND RESPONSE TIME

Figure XI shows that the change of peak current from 210 A to $45 \mathrm{~A}$. When operating current achieves stability, the response time is $10 \mathrm{~ms}$.

TABLE II. THE RESPONSE CHARACTERISTIC OF TWO - STAGE MAGNETIC VALVE MCR WORKING CURRENT

\begin{tabular}{|c|c|c|}
\hline Name & \multicolumn{2}{|c|}{$\begin{array}{c}\text { The response } \\
\text { characteristic of two-stage } \\
\text { magnetic valve MCR }\end{array}$} \\
\hline $\begin{array}{c}\text { Thyristor trigger Angle } \\
\text { change }\left({ }^{\circ}\right)\end{array}$ & $126 \rightarrow 36$ & $36 \rightarrow 126$ \\
\hline $\begin{array}{c}\text { Peak current change }(A) \\
\text { The current response } \\
\text { time (ms) }\end{array}$ & $45 \rightarrow 210$ & $210 \rightarrow 45$ \\
\hline
\end{tabular}

It can be seen from TABLE II that the response of the twotwo magnetic control reactor is very fast. Within a week of $20 \mathrm{~ms}$, MCR can be guaranteed to complete reactive compensation quickly. However, in paper[8] the simulation of matlab is the fastest need of $100 \mathrm{~ms}$. Because the response speed of the new method is reduced to $20 \mathrm{~ms}$ in theory, this method is closer to theoretical analysis and has better reference value

\section{CONCLUSION}

This paper introduces the novel method of combining Simplorer with Maxwell to realize the multi-physical domain 
simulation of the field road, which greatly improves the authenticity and accuracy of simulation and has great reference value for the design and manufacture of MCR in practical engineering. By this way the harmonic and response characteristics of the two-stage MCR are analyzed. Then The following conclusions are drawn from the analysis: It can change the size of the dc control current by changing the trigger angle of thyristor. In this way, the magnetic saturation of iron core is changed under the excitation of dc control current. Finally, it can adjust the capacity of the reactor smoothly; the harmonic characteristic of this method simulation is better than that of matlab simulation; This method realizes the response in a week-wave $20 \mathrm{~ms}$ in simulation and is also better than matlab simulation. In addition, the new approach is closer to theoretical analysis andhas considerable reference value for simulation experiment to reduce the test cost, cycle and so on.It also can provide an experimental theoretical basis for designing controllable reactor with better performance.

\section{REFERENCES}

[1] Bochao Chen. Theory and application of new controllable saturable reactor[M]. Wuhan: Wuhan hydraulic power university press.1999,10

[2] Guohua Gao, Huatai Chen,T Mingxing ian. Design and Simulation of Voltage Control System for Magnetic Saturation Type Controllable Reactor[J].Transformer,2013,50(4)39-42

[3] Zhiyuan Hao. Analysis of magnetic saturation controllable reactor[D].Shandong university,.2015.5

[4] Xingen Liu, Junfeng Zou, Xinnian Sun.Simulation Analysis of MCR Based on MATLAB[J].Power Capacitor \$ Reactive Power Compensation,2015,36(1):35-38

[5] Peng Song, Research on reactive power compensation based on magnetic valve type controllable reactor.[D].Shandong university.2010,4

[6] Guosheng Zhao,Keqin Sun, Ke Yao.Static Reactive Compensation Device Based on the Novel Magnetic Controllable Reactor[J].Journal of Zhengzhou University: Eng Sci,2012,33(6):75-78,91

[7] Cuihua Tian, Baichao Chen.Study of Low Distortion Two-Stage Saturable Magnetically Controlled Reactor[J].Transactions of China Electrotechnical Society,2006,21(1):19-23

[8] Xuxuan Chen, Cuihua Tian,Baichao Chen. Mathematical Model for Harmonics Analysis of the Multi-Stage Saturable Magnetic-Valve Controllable Reactor[J].Transactions of China Electrotechnical Society,2011,26(3):57-63

[9] Peng Wang.Study on response characteristics of magnetic valve type controllable reactor[D].Shandong university, 2014,4

[10] Lei Li. The simulation modeling and characteristic research of magnetic controlled reactor[D].Guangdong University of Technology, 2016.5

[11] Ming Zhong. Research on magnetic valve analysis and fast response characteristics for magnetic control reactor.[D].East China Jiaotong University.

[12] Zhipeng Xu,Guangyou Li.Study on Numerical Calculation of Threephase Three-Limb Controlled Reactor[J].Electrical \& Energy Management Technology.2016,20(13),72-76

[13] Weiping Liao,Study on Fast Response Magnetic halve Controllable Reactor[D].Shandong university

[14] Ren Liu, Guosheng Zhao.Characteristic simulation analysis of threephase magnetic valve type controlled reactor[J].Power System Protection and Control.2011,39(7):110-114

[15] Guosheng Zhao, Zixia Cheng, Keqing Sun. Research on Novel Orthogonal Core Three-phase Magnetic Controllable Reactor[J].Journal of Zhengzhou University (Engineering Science).2014.35(1)15-19

[16] Bo Zhao, Hongliang Zhang. Application of Ansoft12 in engineering electromagnetic field[M].Beijing: China Water Power Press.2010
[17] Lu Zhao, Based on Simplorer field coupling multi-physics domain combined simulation[M],.Beijing: China Water Power Press.2014 